\title{
Case Study: An Improvement of Inspection Approach of Printed Multilayer Circuit Products Related to Visual Based Inspection Technique
}

\author{
Yap Wan Yee ${ }^{1}$, Mohammad Nishat Akhtar ${ }^{2}$ and Elmi Abu Bakar ${ }^{2 *}$ \\ ${ }^{1}$ School of Mechanical Engineering, Engineering Campus, Universiti Sains \\ Malaysia, Nibong Tebal, Pulau Pinang, Malaysia \\ ${ }^{2}$ School of Aerospace Engineering, Engineering Campus, Universiti Sains \\ Malaysia, Nibong Tebal, Pulau Pinang, Malaysia \\ *Corresponding author: meelmi@usm.my
}

Published online: 10 December 2020

To cite this article: Yap Wan Yee, Mohammad Nishat Akhtar and Elmi Abu Bakar (2020). Case study: An improvement of inspection approach of printed multilayer circuit products related to visual based inspection technique. Journal of Engineering Science, 16(2), 1-34, https://doi.org/10.21315/jes2020.16.2.1.

To link to this article: https://doi.org/10.21315/jes2020.16.2.1

\begin{abstract}
Product quality is an important issue in all manufacturing industry nowadays to meet the customers' requirement. In this regard, most of the factory has a special department namely Quality Control (QC) Department which control the product quality. The studied factory is a flexible printed circuit board manufacturer which is located in Bayan Lepas, Pulau Pinang, Malaysia. QC Department of the studied factory has high amount of work-in-progress (WIP). Therefore, the products have to be sent out to subcontractors for quality inspection. However, this method is not economically effective. Hence, the objective of this study was to develop an improved inspection method which will reduce the overall inspection time of the current inspection method (CIM). By reducing the inspection time, productivity of the department will increase and subsequently reduce the amount of WIP. This study is focused on the improvement of one product only. Before the improved inspection method (IIM) of the selected product was developed, performance of the CIM was evaluated by using one of the graphical productivity analysis charting techniques which is flow process chart. It was found that the IIM was able to reduce the inspection time of whole inspection process by $85.06 \mathrm{sec}$ for every 12 panels inspected.
\end{abstract}

Keywords: work-in-progress, current inspection method, improved inspection method, flow process chart 


\section{INTRODUCTION AND BACKGROUND}

Quality control (QC) is an important element in manufacturing industry to ensure high quality products are produced in order to meet customers' needs and requirements. In order to avoid defected products are shipped to customers, tedious inspection has to be carried out after the manufacturing processes. Traditionally, QC tasks were carried out by human being. Nowadays, many automated inspection techniques have been developed to replace the role of human. This is because human performance is not reliable and human being will experience fatigue when they are performing their tasks. However, many companies still prefer to use human instead of automated techniques to perform the QC tasks due to the reason of high capital investment cost which may not be affordable for those companies. Moreover, according to Drury and Sinclair, ${ }^{1}$ human can make better decisions than machines.

The work nature of QC includes sorting, inspecting, testing, weighing and sampling. Among these, visual inspection task is one of the essential methods. ${ }^{1}$ The main function of visual inspection is to determine whether the products achieve the demanded quality or not. Visual inspection basically consists of two primary functions which are visual searching and decision making. ${ }^{2}$ By comparing both elements, searching is more time consuming than decision making. ${ }^{3}$ As a result, there are a lot of researches had been carried out to increase the productivity of QC tasks.

There were many attempts have been made throughout the years to increase the productivity of visual inspection tasks which include utilising or using higher resolution equipment, partially automated inspection methods, introducing visual adding tools and etc. Besides that, there were researches carried out to improve the performance of operators and consequently improve the performance of inspection tasks in terms of productivity, accuracy, effectiveness and efficiency by redesigning or modifying the visual inspection task. This was done by taking into account of various factors that can reduce the stress and fatigue of inspection operators. ${ }^{4}$

In industry nowadays, quality of product always becomes the main concern as customers always demand for high quality products. Hence, inspection tasks have to be carried to make sure that the manufactured products achieve the requisite quality requirement. Among those inspection methods, visual inspection is the most common technique and widely used by industry. Visual inspection consists of two main functions which are visual search and decision making. ${ }^{2}$ 
Visual searching is the attempt to find and locate the defects of products whereas decision making is the act of determining the products whether they can be accepted or rejected. Visual inspection task is successful only when these two functions are performed perfectly. Previously, visual inspection tasks were performed by human inspectors. However, performance of human in visual inspection task is not totally reliable. ${ }^{5}$

Accuracy, effectiveness, efficiency and reliability of human are not comparable with machines. In order to overcome these drawbacks, a lot of new approaches have been developed to increase the performance where these new approaches usually come along with the introduction of machine vision system. Yet, the role of human inspectors cannot be totally eliminated due to the reason of human's better decision-making ability as compared to machines. ${ }^{6}$ Implementation of automated visual inspection system will lead to high investment cost in purchasing related machines. On top of that, developing the automated system is absolutely not an easy task as it involves image processing experts to develop the system's algorithm which will require a long effort. In fact, in many cases, those defects can be very easily detected by human being. ${ }^{7}$ This may be one of the reasons human inspectors are still favored for some of the quality inspection tasks.

As stated previously, visual inspection tasks comprise of two main components which are visual search and decision making. However, visual search consumes much time as compared to decision making in an inspection task. Hence, a lot of tremendous efforts were done to carry out researches in order to increase the efficiency of the visual inspection tasks. From the years, attempts have been made to improve the performance of visual search. In the year of 2009, Lee and $\mathrm{Chan}^{8}$ suggested different magnification methods and the shape of magnifier will affect the performance of inspectors. The effectiveness of linear and differential magnification methods was investigated. Differential magnification is a method where a lower scaling is applied in the high-resolution central fixation area while the more peripheral objects are scaled with a higher magnification power. At the same time, the result in terms of speed, accuracy and Task Load Index (TLX) scores for circular and elliptical magnifier was compared. However, both the differential magnification and elliptical magnifier did not show better result than the conventional method of linear magnification and circular magnifier respectively. ${ }^{8}$ There was another study based on the effect of pacing. When limited time is imposed to a task, it is known as paced task. This study which was carried out by Garrett, Melloy and Gramopadhye 9 in 2001 revealed the relative effectiveness of per-lot pacing compared to per-item pacing. Limited amount of time given for each individual item is called per-item pacing whereas per-lot pacing is that 
limited time is given for a batch of items. From the study, it was found that both pacing condition performed similar accuracy result. On the other hand, per-item search time is consistently faster than per-lot. Moreover, per-item pacing is more manageable. Per-lot item pacing is more efficient in term of speed and hence more applicable to industry inspection. ${ }^{9}$

Previous study shows that job aiding tools can be used to improve performance of inspection operators. As per the research of Tetteh et al. ${ }^{10}$ in 2008, job aiding tools will help to improve accuracy and efficiency of inspection work in terms of shorter search time. This tool will help operators to perform faster in searching element of visual inspection. From the research, job aiding tools can help the operators to avoid covering the same area for more than once because the area scanned is highlighted. Besides that, this study also investigated effect of search strategies where random search strategy was compared to systematic search strategy. Random strategy indicates sampling without replacement whereas systematic strategy implies sampling with replacement. Systematic result presented better result than random search and decreased inspection time. Tetteh and Jiang ${ }^{11}$ performed another study which evaluated the effect of search strategy, task complexity, pacing on visual inspection performance. The expected outcome was that there was interaction between pacing and others two elements. However, results showed that interaction among those elements were not significant. But on the other hand, they found that horizontal search strategy was more effective as compared to vertical search strategy. This occurrence may be due to the reasons of people use to read from left to right. ${ }^{10,11}$

Besides that, there was a research carried out by Jiang et al. ${ }^{12}$ to determine the best inspection system in year 2003. In the study, the performance of the following system was evaluated: (1) a 100\% human inspection system, (2) a computer search/human decision-making inspection system and (3) a human/ computer share search/decision-making inspection system. The combination of human and computer system was known as a hybrid system. The result of this study showed that $100 \%$ human inspection system presented the worst result. The computer search/human decision-making inspection system performed the inspection tasks in a much faster manner. Hence, it was concluded that computer did play an important role especially in the visual search component of visual inspection tasks. Performance of visual inspection tasks could be increased with the introduction of computer technologies. ${ }^{12}$

Chiang and Hwang ${ }^{13}$ conducted a case study analysis to evaluate the performance of human in visual inspection tasks in a glass bottle plant. In that study, two parameters were measured which were the effects of conveyor velocities and 
as well as the number of inspection items on the human performance in a visual inspection task. Result showed that there was no significant relationship among the velocity of conveyor belt and the human inspector performance. In other words, the velocity of conveyor belt does not affect the inspectors' performance. On the other hand, the performance of inspectors was affected by the number of inspection items in which as the number of items increased, the performance of inspectors decreased. ${ }^{13}$

In the year 2004, Yeow and Sen ${ }^{14}$ carried out an ergonomics improvement study in a printed circuit board (PCB) assembly factory. The performance of inspectors was first to be measured. Then, several factors that affect the inspection performance had been identified. These factors include the operators' eye problem subsequently lead to headache, insufficient time for inspection due to the reason of too many features needed to be inspected and ineffective visual inspection where the visual search was carried out randomly. After identifying the factors, several ergonomics interventions were introduced to cure the problems. From that study, it was found that by reducing the usage of magnification glass was able to tackle the problem of operator's eye. Magnification glass was used only when the operators inspected the small and tiny features. In order to cope with the insufficient time for inspection problems, Paul and Rabindra suggested that only the non-electrical components were inspected by the operators. As a result, the number of components that required to be inspected decreased. Finally, by rearranging the sequence of inspecting the PCB board and dividing the PCB into segments, operators found much easier to allocate defects from the PCB hence the defect percentage was reduced. ${ }^{14}$ Table 1 summarises the methods to improve the performance of inspection tasks which discussed previously.

The attempts that had carried out previously as shown in Table 1 were the tremendous effort by the researches with only one purpose which was to increase the performance of the visual inspection tasks. There were attempts to increase the performance by utilising some tools which helped to reduce the visual search time. Besides that, there were studies to investigate effects which affect the performance of human inspectors. By knowing those effects, improvement was made by eliminating or enhancing the effects in order to improve the performance. Thus, the productivity of the tasks was increased.

The results of previous studies were used as a guideline in this project. The methodology to improve the overall performance of the visual inspection tasks for selected product of the company will be discussed in detail in the following section. 
Table 1: Summary of previous attempts to increase performance in visual inspection tasks.

\begin{tabular}{|c|c|c|}
\hline Author & Attempts & Results \\
\hline Lee and $\mathrm{Chan}^{8}$ & $\begin{array}{l}\text { Investigate on difference of } \\
\text { magnification methods (linear } \\
\text { and differential) and shape of } \\
\text { magnifier (circular and elliptic). }\end{array}$ & $\begin{array}{l}\text { Linear magnification and circular } \\
\text { magnifier present better result. }\end{array}$ \\
\hline $\begin{array}{l}\text { Garrett, Melloy and } \\
\text { Gramopadhye }^{9}\end{array}$ & $\begin{array}{l}\text { Study on effect of per-lot } \\
\text { pacing and per-item pacing. }\end{array}$ & $\begin{array}{l}\text { Per-item pacing is more efficient in } \\
\text { term of speed and easy to manage. }\end{array}$ \\
\hline Tetteh et al. ${ }^{10}$ & $\begin{array}{l}\text { Evaluate the effect of job aiding } \\
\text { tools and search strategy. }\end{array}$ & $\begin{array}{l}\text { Job aiding tools can improve the } \\
\text { performance of operators by avoiding } \\
\text { them to scan same area twice. } \\
\text { Systematic search is more effective. }\end{array}$ \\
\hline Tetteh and Jiang ${ }^{11}$ & $\begin{array}{l}\text { Study the effect of search } \\
\text { strategy, task complexity and } \\
\text { pacing. }\end{array}$ & $\begin{array}{l}\text { Interaction of pacing and others } \\
\text { two factors were not significant. } \\
\text { Horizontal search method was more } \\
\text { effective. }\end{array}$ \\
\hline Jiang et al. ${ }^{12}$ & $\begin{array}{l}\text { Determine the best visual } \\
\text { inspection system among: } \\
\text { (1) } 100 \% \text { human inspection, } \\
\text { (2) computer search and human } \\
\text { making decision system and } \\
\text { (3) computer and human search } \\
\text { and decision-making. }\end{array}$ & $\begin{array}{l}\text { Among the evaluated system, } 100 \% \\
\text { human inspection system presented } \\
\text { the worst result. Computer searched } \\
\text { much faster than human. However, } \\
\text { human made better decision. Hence, } \\
\text { performance of visual inspection } \\
\text { system could be increased by } \\
\text { implementing hybrid system which } \\
\text { was the combination of human and } \\
\text { computer. }\end{array}$ \\
\hline $\begin{array}{l}\text { Chiang and } \\
\text { Hwang }^{13}\end{array}$ & $\begin{array}{l}\text { Explore the influence of two } \\
\text { effects on human performance } \\
\text { in visual inspection tasks: } \\
\text { (1) velocities of conveyor and } \\
\text { (2) number of inspection items. }\end{array}$ & $\begin{array}{l}\text { Inspectors' performance was not } \\
\text { affected by the conveyor speed. } \\
\text { Conversely, the performance of } \\
\text { inspectors dropped as the number of } \\
\text { inspection items increased. }\end{array}$ \\
\hline Yeow and $\operatorname{Sen}^{14}$ & $\begin{array}{l}\text { Ergonomics improvement for } \\
\text { visual inspection and tasks. }\end{array}$ & $\begin{array}{l}\text { Reduce the usage of magnification } \\
\text { glass could overcome the operator's } \\
\text { eye problem. Then, the PCB was } \\
\text { divided into segments and rearranged } \\
\text { the inspection sequence to ease the } \\
\text { visual inspection processes. }\end{array}$ \\
\hline
\end{tabular}




\section{METHODOLOGY}

The methodology used throughout the whole project is described in detail in this section. The overall methodology includes the all procedures involved in developing an improved visual inspection method which can increase the performance of the operators of the studied factory. These procedures include the factory visits follows by the selection of a product as the study for this project. Then, the performance of the current inspection method of the selected product is investigated and develops a new inspection method. Finally, the methodology to evaluate the performance of the newly developed method is also discussed. Next section which is Section 3 will present quantitatively the performance of the newly developed method.

The overall methodology described the whole process flow and procedures in order to develop a new approach for visual inspection method of the selected product in which it was illustrated in Figure 1. The first step was to visit the factory. The main focus of the visits was on the QC Department of the factory. After several visits to the factory, one of the factory products was selected for study purpose. Then, the productivity of the current visual inspection method for that selected product was measured by carrying out motion and time studies. Next, by identifying and hence reducing or eliminating those unnecessary motions, a new method of visual inspection for the selected product was developed. Lastly, the performance of the new approach was assessed to determine its effectiveness. If the new inspection was able to increase the performance of operator, then the method would be suggested to the department head for implementation. If not, the method would be revised for improvement or a new method would be developed again.

\subsection{Observation and Data Collection}

Visit to factory was an important initiation step in this project. A clear understanding of the department was needed before the project was carried out. Therefore, the QC Department was visited several times for getting knows the department. During the visits, several questions which start with different interrogative words such as "Why", "Which", "What" and "How" or commonly known as " $5 \mathrm{~W} 1 \mathrm{H}$ approach" were asked in order to understand the department deeper. For example, the first question asked was "How the quality of products is ensured to meet customers' requirement?". According to the QC personnel, in order to perform QC tasks effectively, QC Department of the factory is divided into three sections which are (1) in-coming QC, (2) visual inspection and outgoing QC and finally (3) in-process QC (IPQC) in which each section has its unique role. 
After asking one question, a series of questions by using different interrogative words were asked continuously until a complete understanding of that department was obtained. Table 2 summarises all the questions asked and answers provided by the QC personnel.

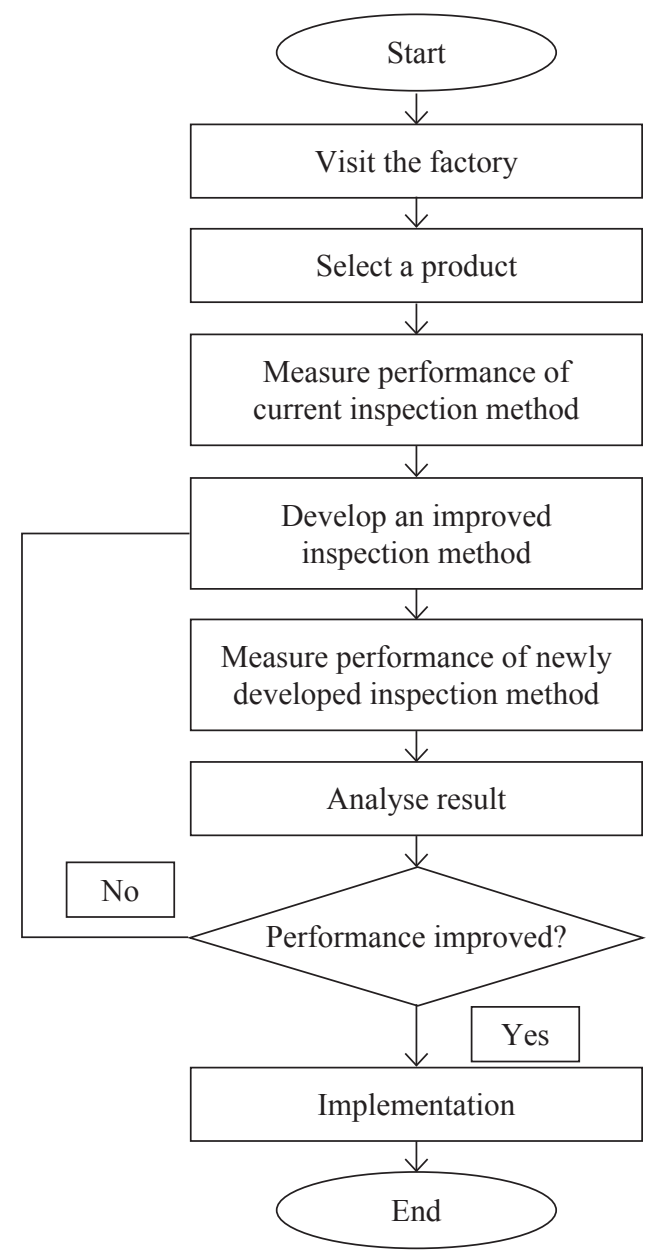

Figure 1: Overall methodology of project.

After questions and answers session with the QC personnel, it was concluded that lack of human resources is the main reason which leads to high amount of work-in-progress (WIP) in Visual Inspection and Outgoing QC section. In order to curb this problem, the FPC boards are inspected by sub-contractors which located quite far away from the factory. Therefore, the performance of the operators needs to be increased so that the productivity of the section will 
subsequently be increased. Then, as the productivity of Visual Inspection and Outgoing QC increases, quantity of products that needs to be sent out to subcontractors for inspection tasks will decrease and hence reduce operating cost of the factory.

\subsection{Case Studies of Selected Product}

From previous step, it was known that Visual Inspection and Outgoing QC section has high WIP. Increase the performance of operators was one of the methods which can reduce the amount of WIP. Therefore, the performance of operators in performing visual inspection tasks was studied. However, there are thousands of products in the factory. Hence, in this project, only one product was selected for study purpose.

Table 2: Questions and answers during visits to the factory.

\begin{tabular}{ll}
\hline No. Questions & Answers \\
\hline $\begin{array}{l}\text { How the qualities of } \\
\text { products are ensured } \\
\text { to meet customers } \\
\text { requirement? }\end{array}$ & $\begin{array}{l}\text { QC Department consists of three sections which are in- } \\
\text { coming, visual inspection and outgoing and in process to } \\
\text { ensure QC tasks are performed effectively. }\end{array}$ \\
2. What is the function \\
of each section?
\end{tabular}$\quad \begin{aligned} & \text { (i) In-coming QC } \\
& \text { Handle quality issues of raw materials before the } \\
& \text { materials can be used for production. This section will } \\
& \text { also perform sampling inspection for products after } \\
& \text { assembly processes from sub-contractors companies. } \\
& \text { (ii) Visual Inspection and Outgoing QC } \\
& \text { Visually inspection the partially finished and finished } \\
& \text { products before shipping to next process. Visual } \\
& \text { inspection performs 100\% inspection whereas outgoing } \\
& \text { performs sampling inspection. } \\
& \text { (iii) IPQC } \\
& \text { Control the machines' condition everyday so that the } \\
& \text { products produced during the manufacturing processes } \\
& \text { achieve the quality. Sampling inspection is performed } \\
& \text { for the products after undergoing some processes. } \\
& \text { If there are defects, rework process can be carried out. } \\
& \text { All the sections are critical since they are equally critical. } \\
& \text { However, Visual Inspection and Outgoing section has a lot } \\
& \text { of WIP. }\end{aligned}$


Table 2 (Continued)

\begin{tabular}{cll}
\hline No. & Questions & Answers \\
\hline 4. & $\begin{array}{l}\text { Why Visual Inspection } \\
\text { and Outgoing section } \\
\text { has a lot of WIP? }\end{array}$ & $\begin{array}{l}\text { This section has to perform } 100 \% \text { inspection for the products } \\
\text { whereas the other two sections are sampling inspection only. } \\
\text { Besides that, lack of human resource is another main reason } \\
\text { which causes high WIP. }\end{array}$ \\
5. How to overcome this & $\begin{array}{l}\text { There are two sub-contractors which will assist in visual } \\
\text { inspection. One of the sun-contractors located in Kulim, }\end{array}$ \\
& $\begin{array}{l}\text { Kedah, Malaysia whereas the other located in Alor Setar, } \\
\text { Kedah, Malaysia. }\end{array}$ \\
6. What are the problems & $\begin{array}{l}\text { These sub-contractors are located far away from the factory. } \\
\text { Travelling time of the products to the subcontractors is } \\
\text { considered as a waste. }\end{array}$ \\
\hline
\end{tabular}

After discussion with the Visual Inspection and Outgoing QC section head, she selected PMC parts as the product to be studied in this project. PMC parts are products which are used for automotive purposes. They are rectangular in shape. One piece of PMC part is known as one panel. In each panel, it contains several identical subpanels which are known as board. One panel may contain different amount of boards for example three boards per panel. There are almost hundred types of PMC parts. Therefore, only one type of PMC part was chosen for further study.

There were several reasons for selecting PMC part as the focus of the study of this project. The reasons are as listed:

1. PMC part does not have end of life (EOL): Products which have EOL will not be selected. This is because they are not long run products which mean the products will not be produced anymore after sometimes. Method to increase performance of inspection method for that product may not be useful after the products are stopped for production. Since PMC does not have EOL, therefore, it was selected.

2. Newly developed method to improve the performance of current inspection method can be applicable to other PMC parts: Almost all PMC parts have similar shape which is in long rectangular shape and having some boards in one panel. Therefore, once a new inspection method is developed, the method will be applicable to other PMC parts.

3. PMC part always has bad feedback from customers: since PMC part is in a long rectangular shape with a lot of features inside the panel. Hence, it always happens the case where many defect features cannot be detected and become escapees. Such escapees will be treated as good part and send 
to customers. When the customers receive the defected products, they will voice out their feedback to the factory regarding this issue of receiving defect products.

Finally, the PMC part selected for this project was Product 12951. Each panel of Product 12951 consists of three boards. There are total seven fiducial marks and three stiffeners. The schematic drawing of the Product 12951 was shown in Figure 2.

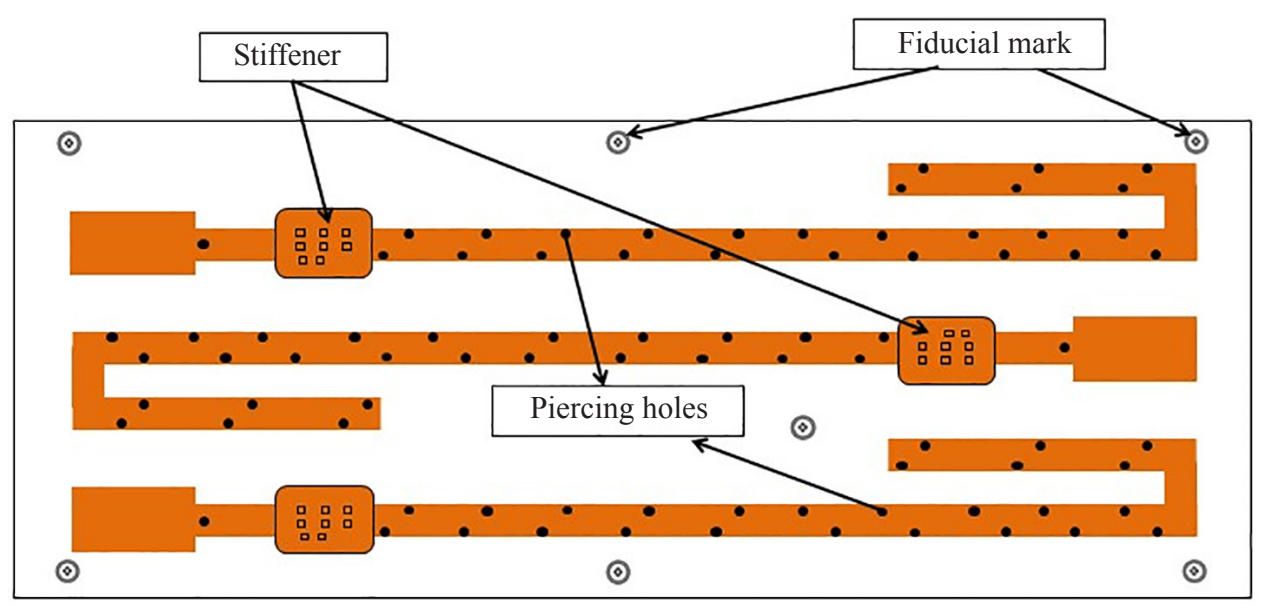

Figure 2: Schematic drawing of Product 12951.

\subsection{Measure Performance of Current Inspection Method}

After selecting product to be studied, before improved approach was developed, the performance or productivity of current method needed to be measured. There are several methods which are very useful in measuring performance of method that currently practiced by the operator. One of the methods is position analysis questionnaire (PAQ). This method is used to predict the performance of operator. However, this method is mainly focus on predicting performance of retarded operators. ${ }^{15}$ Hence this method was not suitable being used in this project. Therefore, there was another method suggested which was graphical productivity analysis (GPA). GPA involves the usage of charting technique. ${ }^{16}$ Activities that performed in producing a product or service can be described by using charting techniques. Hence, GPA was more suitable to be used in this project as compared to PAQ. In the charting techniques, several standard symbols are used to communicate on the charts. The symbols are illustrated in Table 3. 
Table 3: Charting symbol used in charting techniques.

$\begin{array}{lll}\text { Charting symbol } & \text { Process } & \text { Description } \\ \text { Operation } & \begin{array}{l}\text { Process of adding value to the product in order to } \\ \text { make the product become more useful. }\end{array} \\ \text { Storage } & \begin{array}{l}\text { Process of moving the product from one location to } \\ \text { other. }\end{array} \\ \text { Process of comparing characteristic of the product } \\ \text { with a standard. }\end{array}$

After understanding the symbols used in the charting technique, it was important to know types of charting techniques which can be used for different purposes. Table 4 described four types of standard charts which are used widely. ${ }^{16}$

Table 4: Types of standard charts.

\begin{tabular}{cll}
\hline No. & Standard charts & Description \\
\hline 1 & Operation process chart & $\begin{array}{l}\text { This chart illustrates a broad view of the entire } \\
\text { process of producing the products. }\end{array}$ \\
2 & Flow process chart & $\begin{array}{l}\text { This chart present detail steps or path taken in a } \\
\text { particular process. }\end{array}$ \\
3 & Left-hand/right-hand chart & $\begin{array}{l}\text { This chart shows the very fine detail process of an } \\
\text { operator motion in completing a task. } \\
\text { This chart shows the relationship of activity time } \\
\text { and idle time. }\end{array}$ \\
\hline
\end{tabular}

In the proposed work, among the four types of standard charts, flow process chart was selected as the charting technique to be used. This was because this chart is able to present clearly each step taken in the inspection process associated with the time taken to perform each step. By using this technique, unnecessary motions or steps in the process can be detected easily. Hence, by eliminating the unnecessary steps, the inspection method can be improved. Multiple activity chart was not a suitable selection since this project focused in one inspection method in one time only. Left-hand/right-hand chart involves very fine detail of the process which was not needed in the study. Therefore, flow process chart was the best selection. 


\subsection{Develop an Improved Inspection Method}

After the measurement of current inspection method, a new inspection method was developed. According to Lawrence, before an improvement can be made, several questions should be asked. ${ }^{16}$

1. Can the operation be eliminated? By eliminating those unnecessary steps, productivity of the operator will gradually be increased.

2. Can the operation be combined? Combination of the steps will cause less stops or starts of the processes and finally increase the productivity.

3. Can the sequence of activities be changed? Sequence of activity will affect the productivity of a process. A disorganised sequence of a process will have lower productivity than a process which is orderly organised.

4. Can the activities be simplified? Complex motion will cause the operator more difficult to perform the process. Hence, by simplifying the process, it will increase the operators' productivity.

If there are unnecessary motions, then these motions need to be eliminated. Similarly, if it is possible, combine the processes which can be combined. Thus, by asking these questions, a new inspection method can be developed.

\subsection{Measure Performance of Improved Inspection Method}

The purpose of developing a new inspection method is to increase the productivity. Hence, the performance of the improved inspection method needs to be evaluated and compared to the current method. If the newly developed method can increase the productivity, then it can be said that the method development is successful. However, if the new method cannot increase the performance, then the method is revised and modifications are made.

Similarly, flow process chart technique was used to evaluate the performance of newly developed inspection method.

In order to obtain comparable result, total of 12 panels were used for the analysis of both current and new developed method. Total time taken to perform the tasks for current method and new method was compared. If the total time was reduced, then the new method development was successful. A detail methodology is important in order to develop an improvement plan for a current process or method. This project did not involve sophisticated methodology to develop a new inspection method. Instead, it involved only simply analysis such as " $5 \mathrm{~W} 1 \mathrm{H}$ " approach, flow process chart technique which involved the time and motion study of operators as well. The result will be discussed in detail in next section. 


\section{RESULTS AND DISCUSSIONS}

\subsection{Measure Performance of Current Inspection Method}

Before the performance of the current inspection method can be measured, the process flow or sequences of the current inspection method was observed first. This was carried out by first interviewing supervisor of Visual Inspection and Outgoing QC section. This interview session provided a brief idea of how the inspection of Product 12951 was carried out. After that, one of the operators was requested to perform the whole inspection process. Every single motion and time taken to perform the motions was recorded and tabulated.

\subsubsection{Process flow of current inspection method}

From the interview session and observation, the inspection process flow of Product 12951 is as shown in Figure 3.

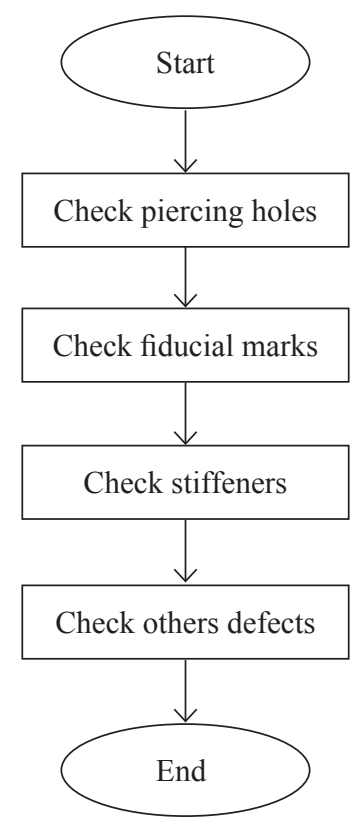

Figure 3: Process flow of current inspection method.

First of all, operators will take one lot of the product from the WIP rack as shown in Figure 4. Then the products will be put on the stand. Products that were placed on left hand side of the operators indicated before checking. 


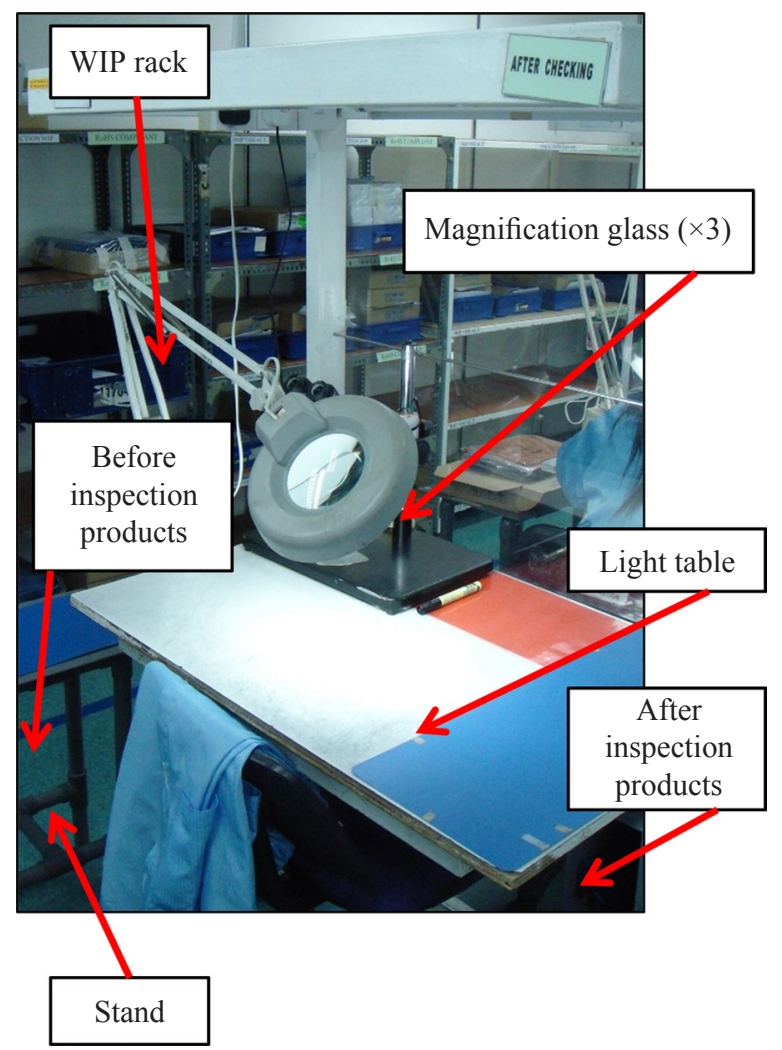

Figure 4: Work place for inspection process of Product 12951.

As the products taken from the WIP rack, they were arranged orderly and separated by using the blue colour separator. Between two separators, there were four panels which were arranged in two rows where each row with two panels as illustrated in Figure 5. The panels were put back to back which means back side of the panels faced each other.

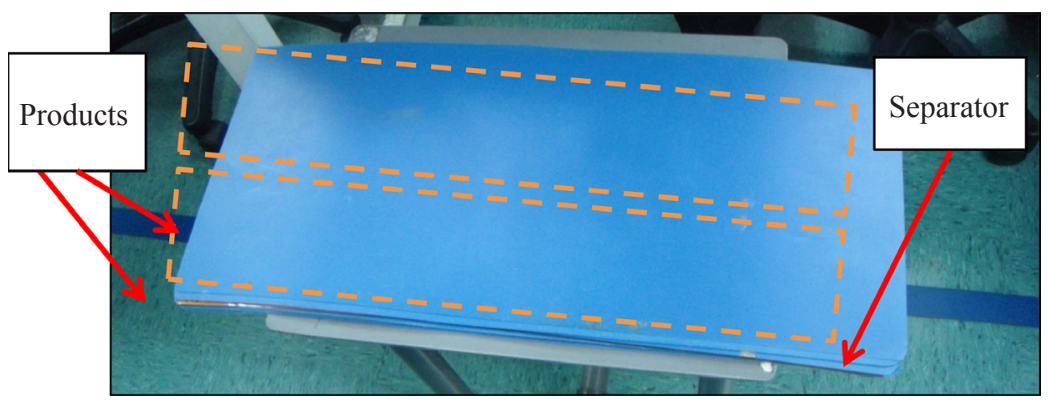

Figure 5: Separators and products. 
The process started by checking piercing holes first. First of all, the separator needed to be taken away and put at right hand side of the table as shown in Figure 6. Three panels of the products were calculated and the panels were aligned properly. The three panels were lifted up to check the piercing holes. Then, the panels were put on table in order to check all the seven fiducial marks of each panel. Finally, the panels were put aside on the right of the table. This process flow continued and continued until all the panels were checked for the piercing holes and fiducial marks.

After completing the first and second steps, the third step was to checked stiffeners. Before the third step started, the inspected products which were initially on the right hand side were move to the stand on the left hand side again. This indicated that the products were again unchecked. The process started again by taking away the separator and put it aside on the right. One panel was taken and put on the light table. Checked stiffeners were marked by marker pen. Next, the checked panel was put on the right side. This process continued for all the panels until the end.

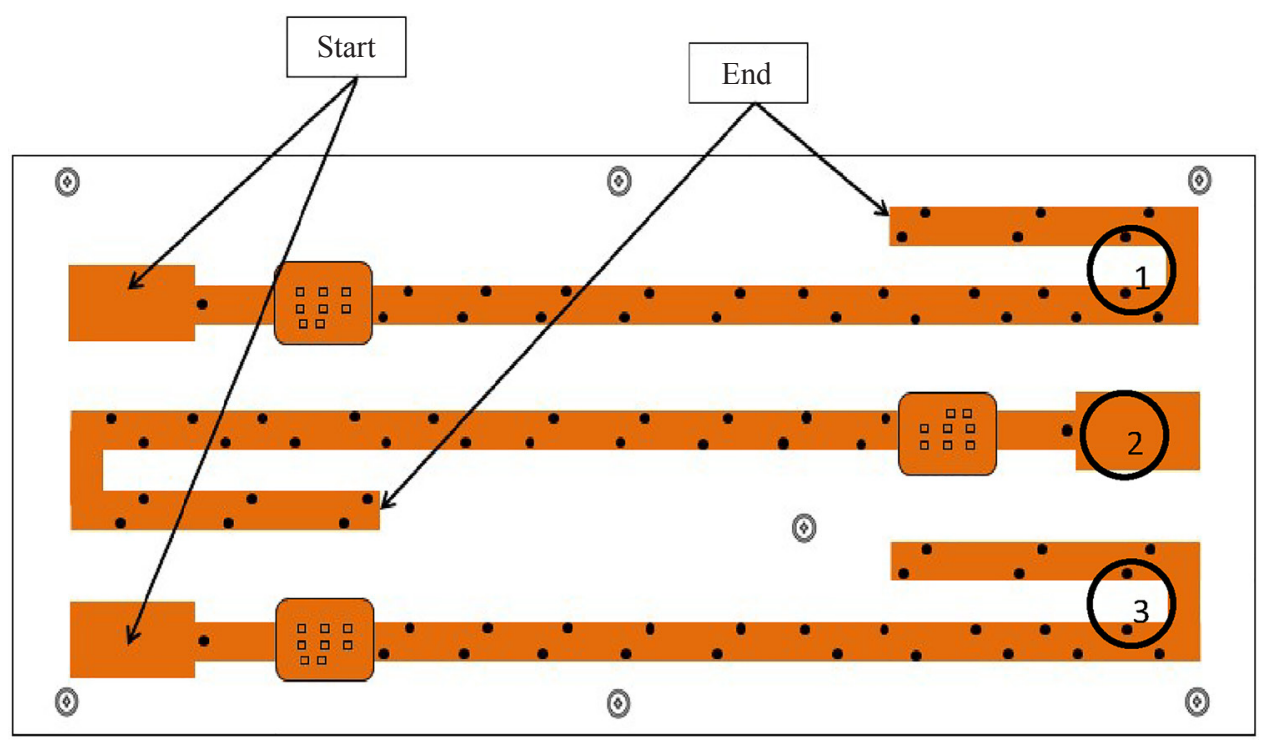

Figure 6: Other defects inspection sequences.

Finally, the final process was the inspection for other defects. Examples of other defects included discoloration, scratches, wrinkles, excess cover lay and so on. Similarly, to previous step, the panels on the right needed to be transfer to the stand on left side. The process started with the inspection of the first panel labelled as " 1 ". The inspection began from the "start" point and terminated at the "end 
point". This process was repeated for the other two boards labelled as " 2 " and " 3 ". After inspection, the panel was put aside on the "after checking" area. The process ended as all the panels were inspected. The overall inspection process of Product 12951 was end if the last process of inspecting other defects ended.

\subsubsection{Flow process chart of current method}

After recognising all the processes involved in the current inspection method, the productivity of the current method needed to be evaluated. As discussed in Section 3, the method used was flow process chart. The flow process chart was divided into three sections which were (1) checking piercing holes and fiducial marks, (2) checking stiffener and (3) checking other defects. Each section describes separately every single motion involved in the inspection process.

\subsubsection{Analysis of checking piercing holes and fiducial marks}

As discussed earlier, total of 12 panels were used in the analysis. Every step in the process of checking piercing holes and fiducial marks were recorded and tabulated in Table 5.

Table 5: Flow process chart of checking piercing holes and fiducial marks.

\begin{tabular}{|c|c|c|c|c|c|c|c|c|c|}
\hline \multirow{2}{*}{ Step } & \multirow{2}{*}{ 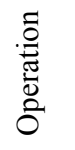 } & \multirow{2}{*}{ 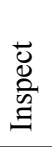 } & \multirow{2}{*}{ 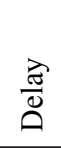 } & \multirow{2}{*}{ 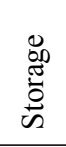 } & \multirow{2}{*}{ Work description } & \multicolumn{4}{|c|}{ Time (sec) } \\
\hline & & & & & & 1 & 2 & 3 & Average \\
\hline 1 & & & & & $\begin{array}{l}\text { Take away the } \\
\text { separator }\end{array}$ & 3.46 & 3.01 & 4.84 & 3.77 \\
\hline 2 & & & & & Take three panels & 5.96 & 6.28 & 4.95 & 5.73 \\
\hline 3 & & & & & $\begin{array}{l}\text { Align three panels } \\
\text { properly }\end{array}$ & 3.64 & 3.61 & 3.82 & 3.69 \\
\hline 4 & & & & & $\begin{array}{l}\text { Check piercing } \\
\text { holes }\end{array}$ & 13.9 & 15.7 & 17.2 & 15.6 \\
\hline 5 & & & & & $\begin{array}{l}\text { Check fiducial } \\
\text { marks }\end{array}$ & 19.3 & 15.9 & 17.3 & 17.5 \\
\hline 6 & & & & & $\begin{array}{l}\text { Align and put aside } \\
\text { the three panels }\end{array}$ & 4.96 & 6.33 & 4.82 & 5.37 \\
\hline 7 & & & & & Take one panel & 1.43 & 1.37 & 1.58 & 1.46 \\
\hline
\end{tabular}


Table 5 (Continued)

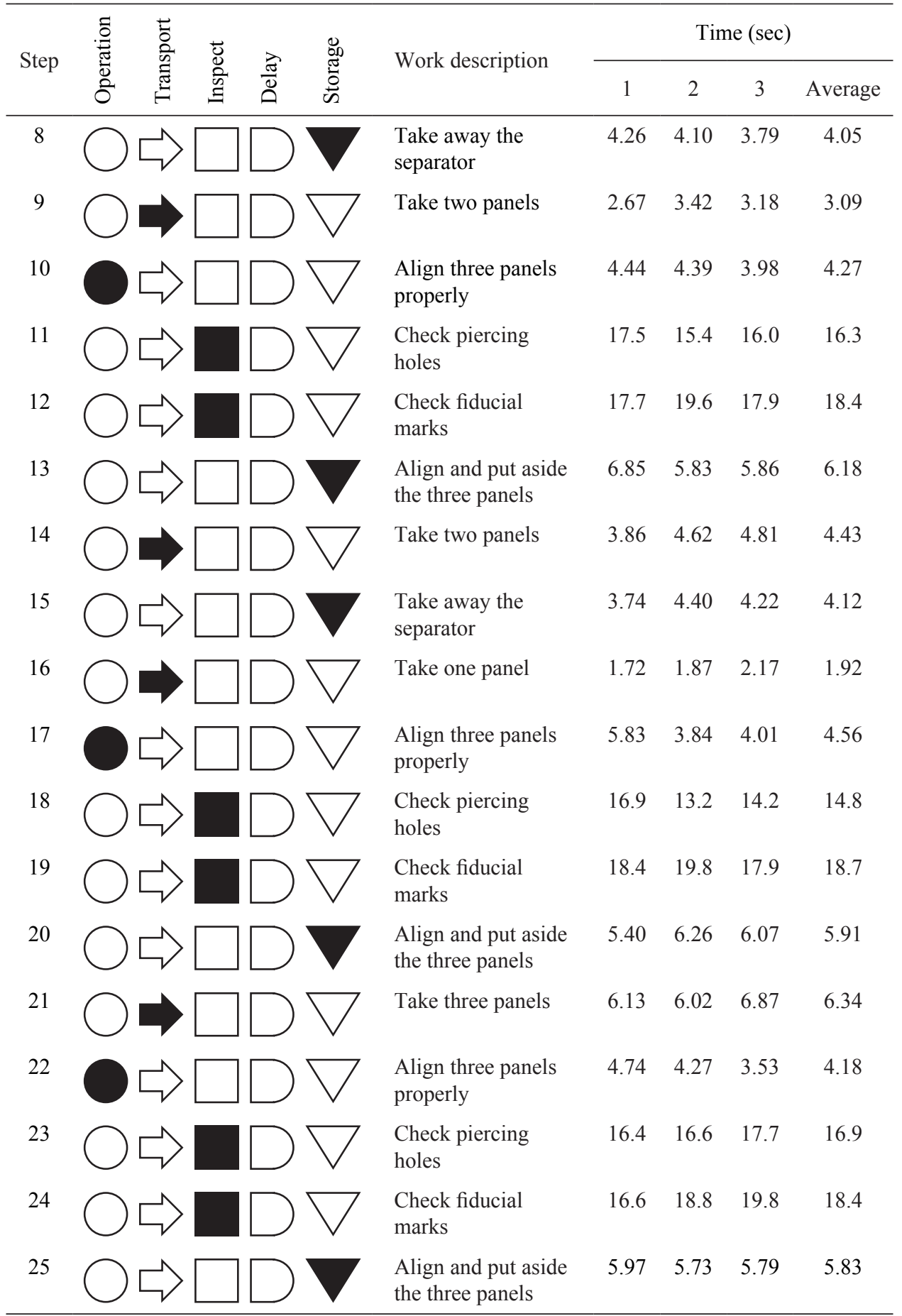


As shown in Table 5, in order to check piercing holes and fiducial marks of 12 panels of Product 12951, it comprised of 25 motions. There were four operation motions, six transport motions, eight inspect motions and seven storage motions. Total time used to complete these 25 motions was $211.50 \mathrm{sec}$.

\subsubsection{Analysis of checking stiffeners}

After the processes of checking piercing holes and fiducial marks, process of checking stiffeners was carried out. Table 6 presented the process flow chart for the process of checking stiffener.

Table 6: Flow process chart of checking stiffeners.

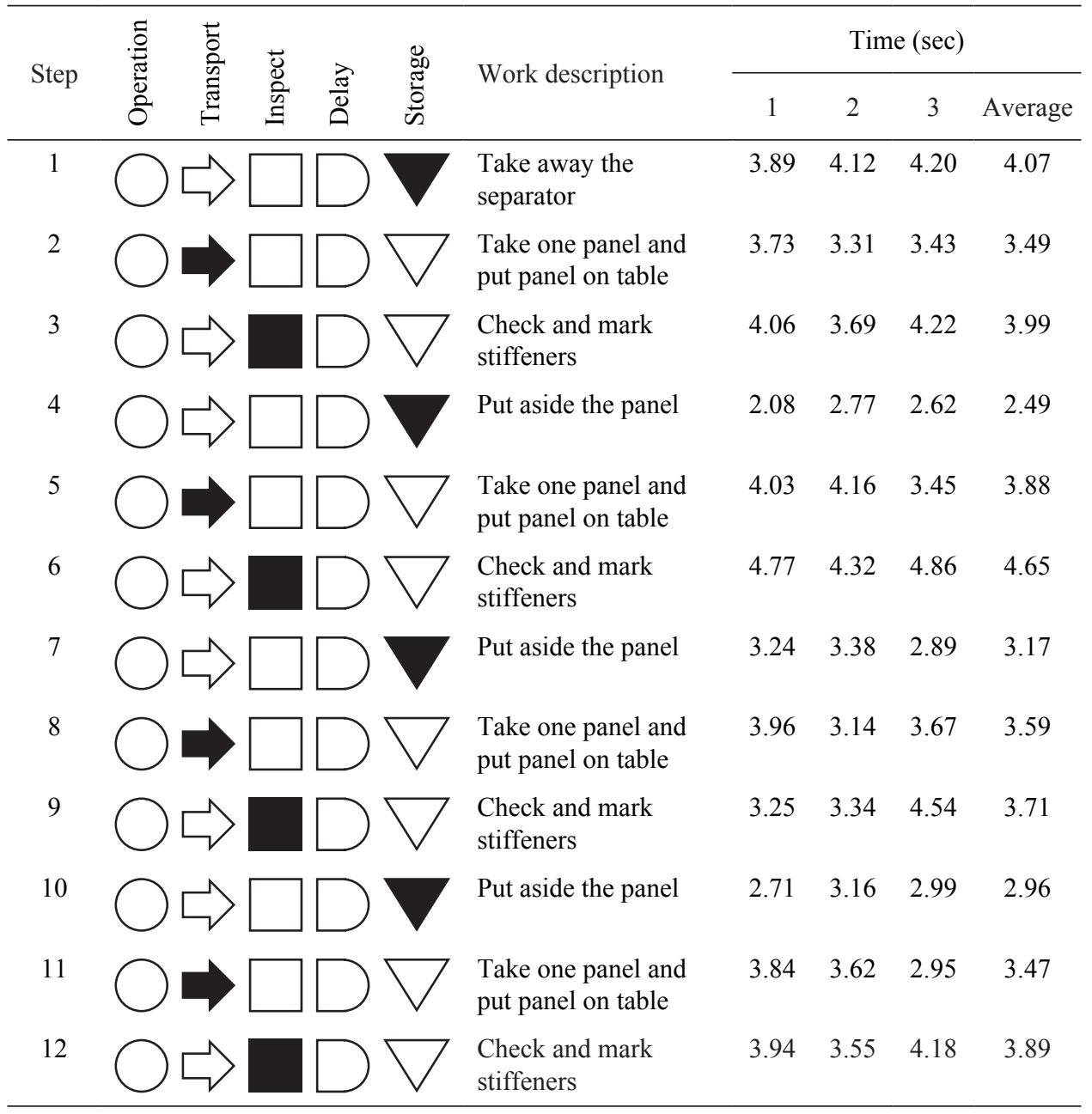


Table 6 (Continued)

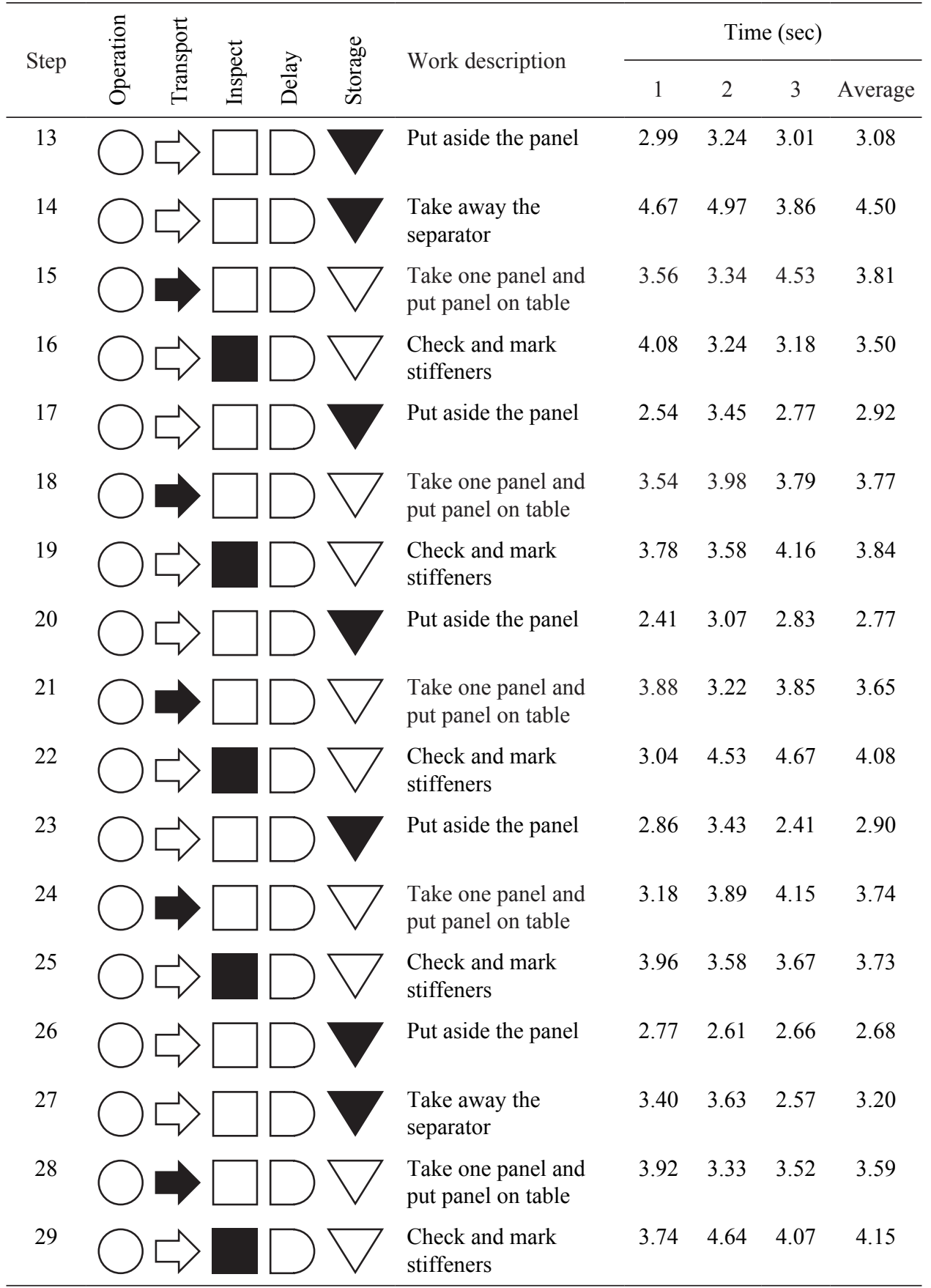


Table 6 (Continued)

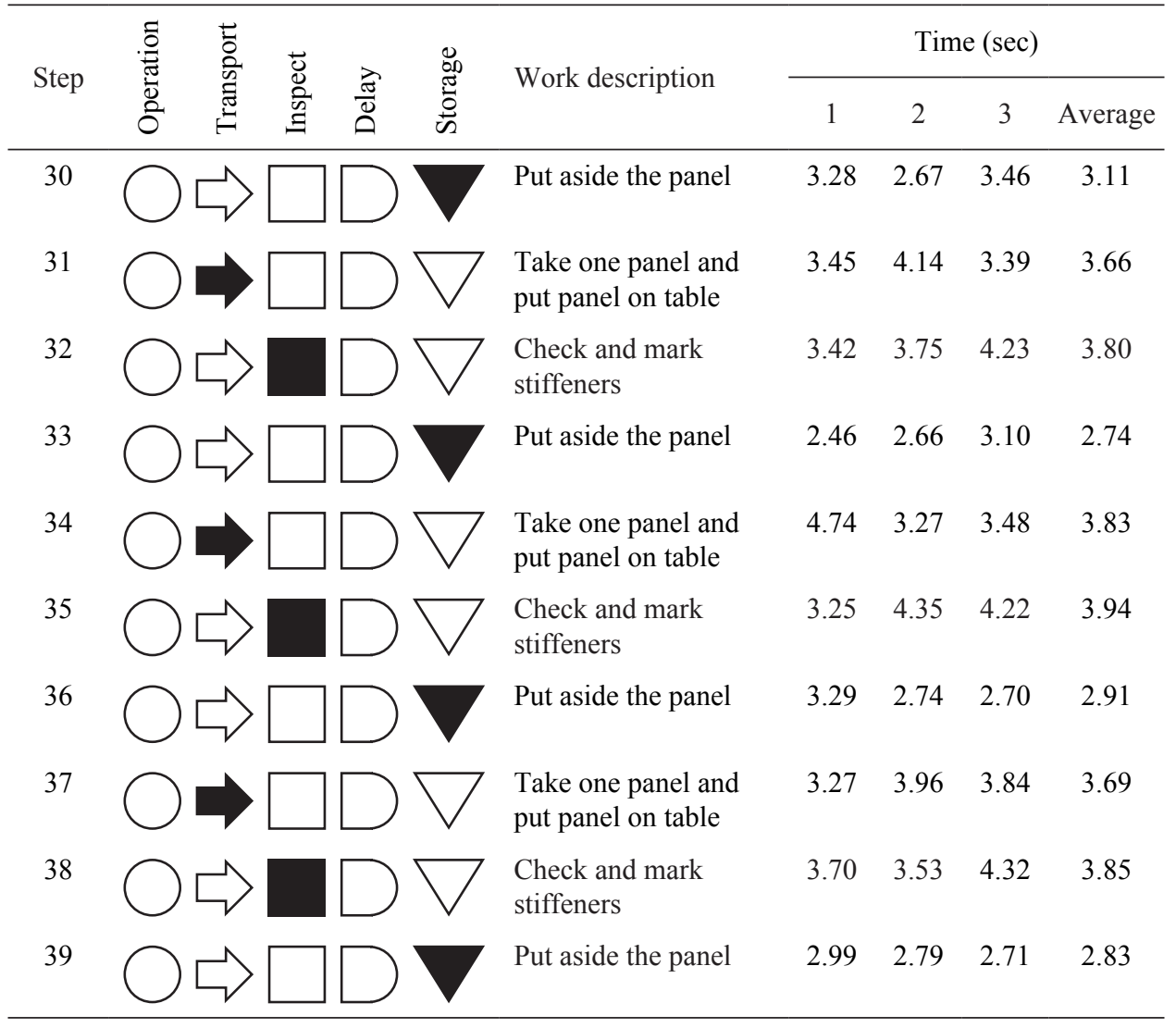

Checking stiffener process took time of around $137.63 \mathrm{sec}$ for 12 panels. However, this did not include time taken to take and put the marker pen as well as well time consumed to open and close the pen cap. In this process, marker pen was taken and put down for 12 times. Besides that, the marker pen was opened and closed for 12 times as well. Each motion of take and put marker pen, open and close pen cap consumed one sec each. Therefore, the total time for this process was $185.63 \mathrm{sec}$.

This process consisted of 39 motions which comprised of 12 transportation motions and 12 inspection motions as well as 15 storage motions. For the motion of taking one panel and putting the panel on the table, if fact, the panel was turned to the back side since stiffener needed to be checked from the back side of the panel. 


\subsubsection{Analysis of checking other defects}

The final process of the inspection for Product 12951 was checking others defects. The motions and time study of this process was as tabulated in Table 7.

Table 7: Flow process chart of checking other defects.

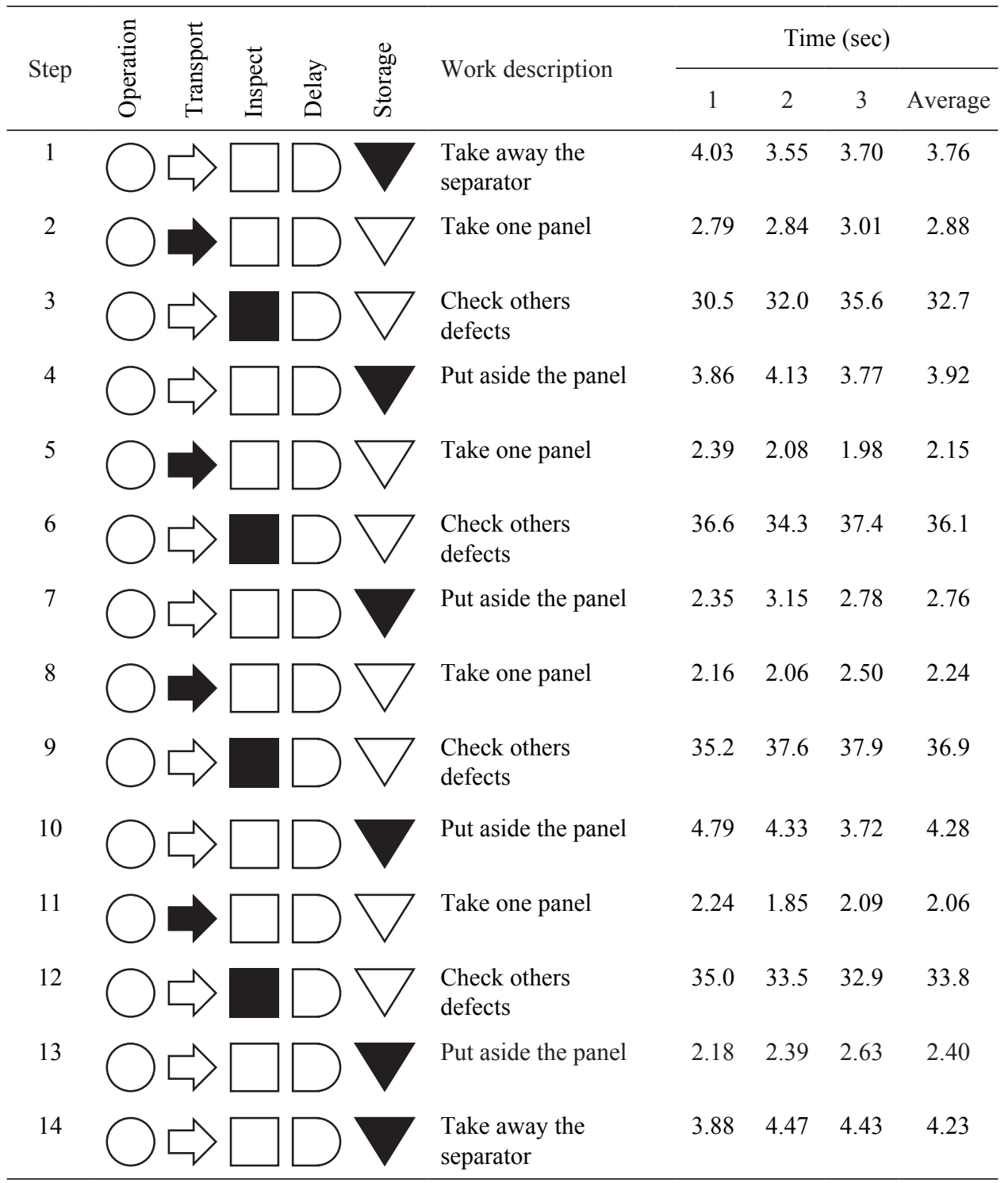


Table 7 (Continued)

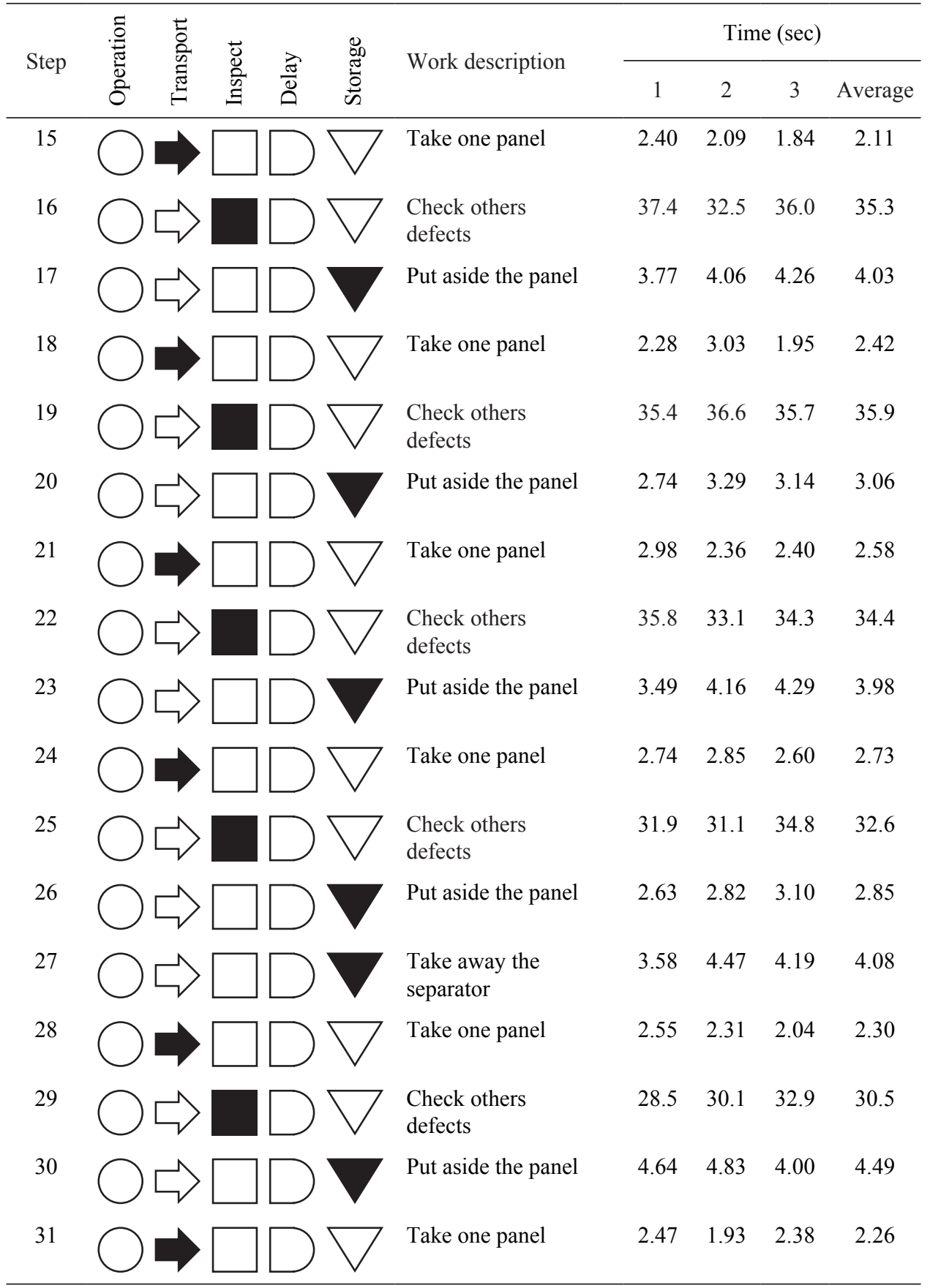


Table 7 (Continued)

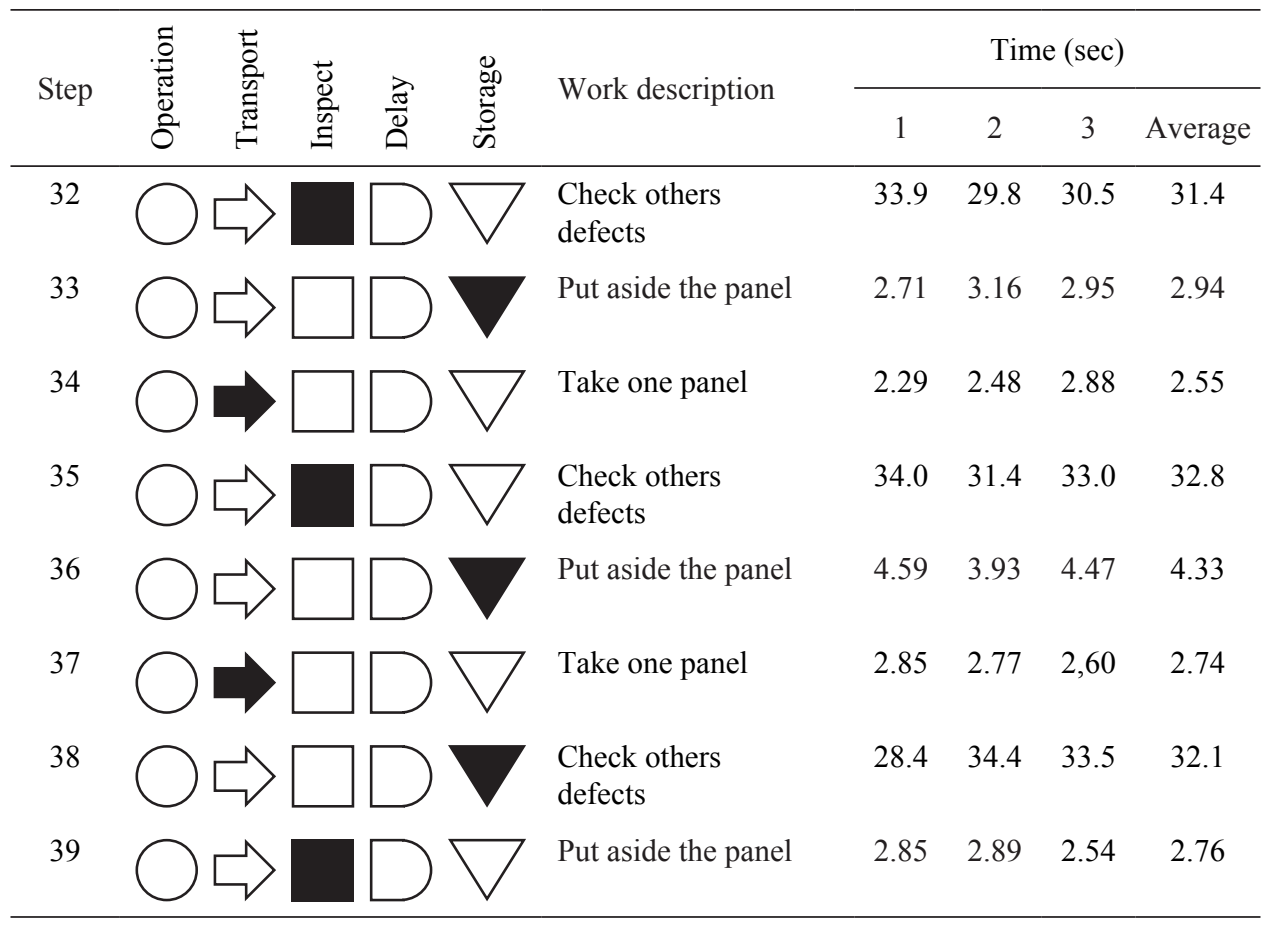

This process took relatively longer time because it involved the inspection of three boards in each panel. After the inspection, the products needed to be arranged back to the initial arrangement as described in previous section. Hence the time taken to put aside the panels were different for different sequence in the process. For example, time taken to perform steps 4 and 7 was different even though the motion was the same. For step 4, back side of the panel needed to be turned and faced upwards before placed on the separator. For step 7, the panel was placed directly on top of the previous panel. Therefore, time was saved in this case without turning the panel. Total time taken was $487.39 \mathrm{sec}$. There were total 39 motions involved in this process where the motions were 12 each for transportation and inspection motions. There were 15 storage motions.

As a conclusion, the total time taken to carry out the whole inspection process of 12 panels of the Product 12951 consumed total of $884.52 \mathrm{sec}$ or equivalent to around $14.7 \mathrm{~min}$. 


\subsection{Develop an Improved Inspection Method}

From previous section, it was discussed that in order to develop an improved inspection method, questions as listed below needed to be asked:

1. Can the operation be eliminated?

2. Can the operation be combined?

3. Can the sequence of activities be changed?

4. Can the activities be simplified?

In previous analysis of current inspection method, it was found that there were a lot of transportation motions and storage motions in all the three processes. In fact, transportation and storage motions were a kind of waste. By reducing these wastes, the inspection method can be improved in terms of shorter time consumed in performing the inspections.

\subsubsection{Improvement for checking piercing holes and fiducial marks}

In this process of checking piercing holes and fiducial marks, the sequences could be changed in order to save time. Current method checked piercing holes first followed by fiducial marks. These sequences should be changed into checking fiducial marks first then only piercing holes. Current method started by taking three panels and then aligned the panels properly in order to check the piercing holes. Then the panels were put on the table to perform fiducial marks checking. Before the panels were dispatched to the right-hand side, the panels needed to be aligned again. This motion was a waste where the second time panel alignment did not add any value to the products' inspection. If the sequence was reversed whereby checking fiducial marks first, the second time alignment was eliminated. This was because checking of fiducial marks needed not align the panels properly. After checking the fiducial marks, then only the panels were aligned properly for the checking of piercing holes. Without the need of second time alignment, the panels could be directly place on the separator located on right hand side.

Besides that, instead of taking three panels once, it was suggested that four panels were taken in one time. Since every four panels were separated by one separator, by taking all the four panels in one time, this could eliminate the time taken to calculate the number of panels that should be taken which was three panels. 


\subsubsection{Improvement for checking stiffeners}

Instead of checking one panel per time, it was suggested to perform stiffeners checking of two panels in one time. This improvement was actually the combination of processes which could cause less stops and starts during the inspection process. Two panels were taken at once. The panels were turned and hence placed parallel on the light table as shown in Figure 7. This improvement was made in order to reduce the frequency of operator take and open marker pen cap, close cap and put down the pen after checking. Each process took around one sec and by reduce the frequency of these steps could reduce the total inspection time.

This process of checking stiffener was suggested to be performed lastly. This was because by arranging the panels in pair as shown in Figure 7, it actually eased the process of arranging the panels back to original the arrangement. After checking, panel number 2 were turned and placed on top of panel number 1 where back side of both panels faced each other. Then, the two panels were moved together and placed on the separator. From the analysis in previous subsection, a lot of time was wasted in putting aside the panels to the after checking area since the panels were required to be arranged back to original arrangement. It was observed that operators wasted time to turn the panels in order to orient the panels in the correct arrangement. Therefore, by changing checking stiffener process as the last process may reduce the overall inspection time.

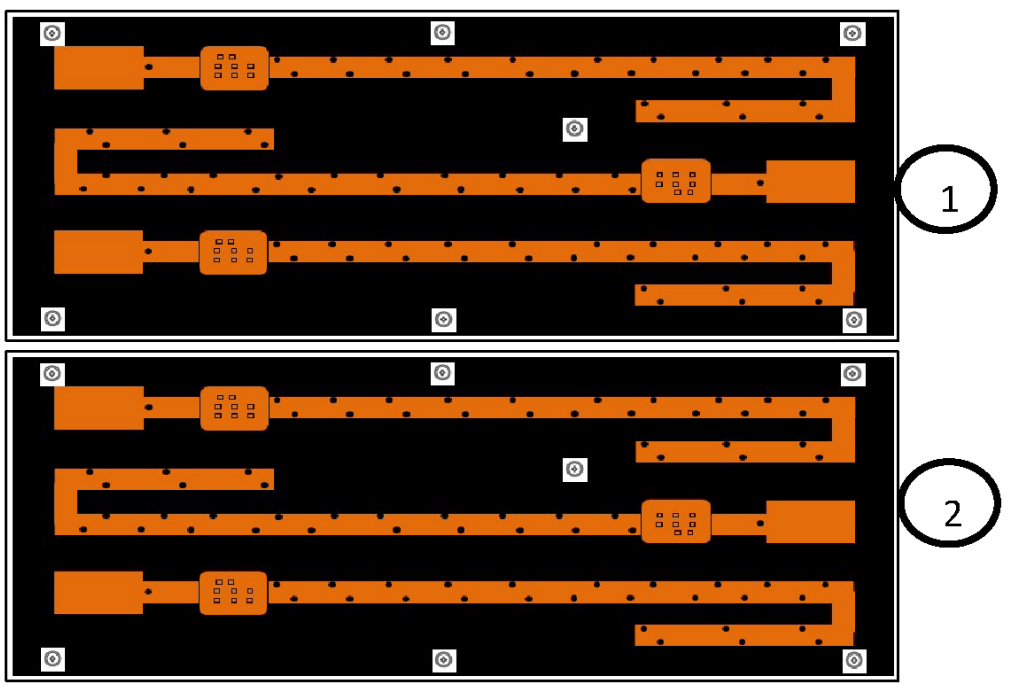

Figure 7: Arrangement of two panels on light table. 


\subsubsection{Improvement for checking other defects}

This process took the longest time as compared to the other two processes. This was because every feature except piercing holes, fiducial marks and stiffeners needed to be checked. Since the product is in long rectangular shape, hence operators will easily miss the defected feature and treat the defected features as good part and eventually sending the defected products to the customers. Hence, it was suggested that this process to be carried out first among the other two processes. According to Hockey et al., when the operators are fresh and energetic, they can perform more difficult jobs; when they feel tired, they will eventually switch to jobs which are less demanding. ${ }^{17}$

\subsection{Measure Performance of Improved Inspection Method}

An improved inspection method was developed based on the suggestions made in this paper. Figure 8 illustrated the overall process flow for improved inspection method for Product 12951.

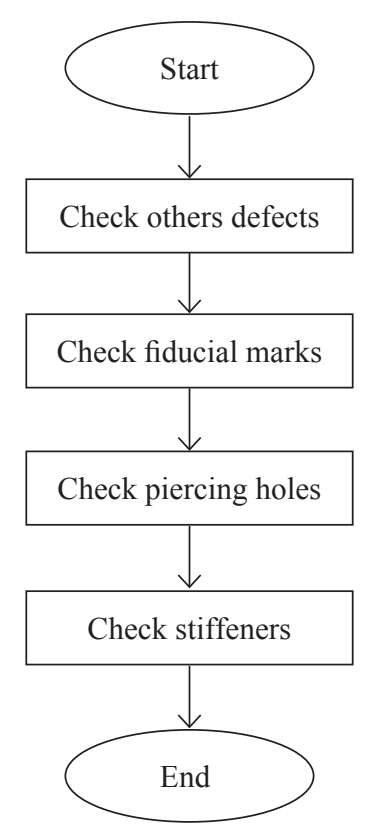

Figure 8: Process flow of improved inspection method. 


\subsubsection{Flow process chart for improvement inspection method}

Same as current inspection method performance measurement, process flow chart was also used to evaluate the performance of improved inspection method for Product 12951.

\subsubsection{Analysis of checking other defects (improved)}

Process of checking other defects were performed first. The number of motions involved in this process remained the same as 39 motions. Not much quantitative improvement could be measured for this process. However, by performing this process first could reduce the number of escapees. This was because the operators are in fresh and energetic state when they perform this checking which is the most difficult part compared to the other two processes which are checking piercing holes and fiducial marks as well as the process of checking stiffener.

\subsubsection{Analysis of checking fiducial marks and piercing holes (improved)}

As discussed in previous section, it was suggested that fiducial marks were checked before the piercing holes in order to eliminate the redundant motion of aligning the panels. Table 8 tabulated the time taken to carry out the motion in this process.

Table 8: Flow process chart of checking fiducial marks and piercing holes (improved).

\begin{tabular}{|c|c|c|c|c|c|c|c|c|c|}
\hline \multirow{2}{*}{ Step } & \multirow{2}{*}{ 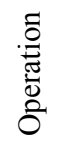 } & \multirow{2}{*}{$\begin{array}{l}\text { U. } \\
\stackrel{\Xi}{0} \\
\vdots \\
\vdots\end{array}$} & \multirow{2}{*}{$\frac{\vec{\jmath}}{0}$} & \multirow{2}{*}{$\begin{array}{l}0 \\
\ddot{0} \\
\frac{\pi}{0} \\
\dot{0} \\
\dot{\omega}\end{array}$} & \multirow{2}{*}{ Work description } & \multicolumn{4}{|c|}{ Time (sec) } \\
\hline & & & & & & 1 & 2 & 3 & Average \\
\hline 1 & & & & & Take away separator & 3.46 & 3.01 & 4.84 & 3.77 \\
\hline 2 & & & & & $\begin{array}{l}\text { Take all the four } \\
\text { panels }\end{array}$ & 3.41 & 4.04 & 3.59 & 3.68 \\
\hline 3 & & & & & Check fiducial marks & 24.0 & 24.5 & 26.2 & 24.9 \\
\hline 4 & & & & & $\begin{array}{l}\text { Align the four panels } \\
\text { properly }\end{array}$ & 4.31 & 6.38 & 4.97 & 5.22 \\
\hline 5 & & & & & Check piercing holes & 17.3 & 16.7 & 14.6 & 16.2 \\
\hline 6 & & & & & $\begin{array}{l}\text { Put aside the four } \\
\text { panels }\end{array}$ & 3.06 & 1.94 & 2.11 & 2.37 \\
\hline
\end{tabular}


Table 8 (Continued)

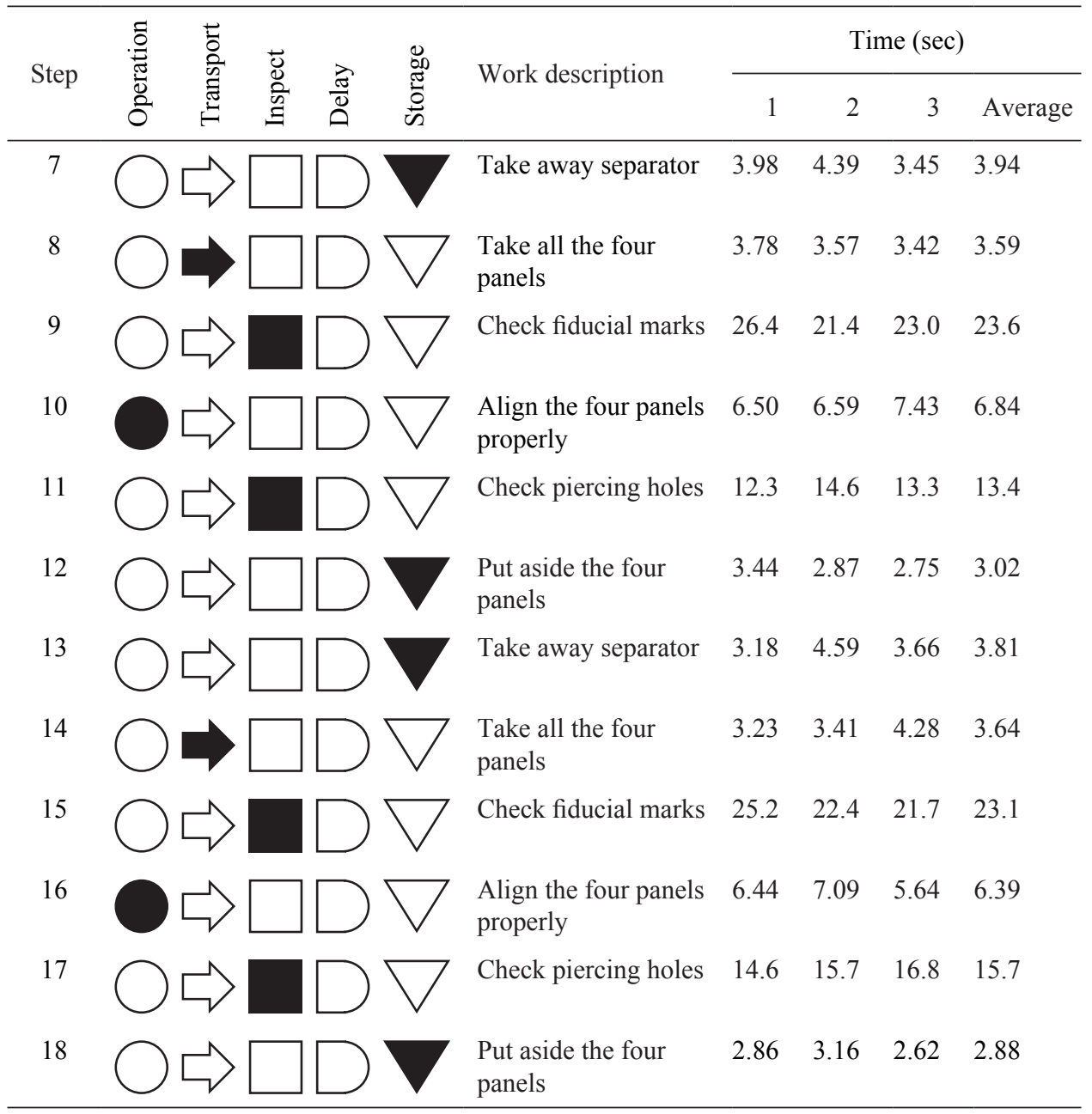

As compared to the inspection method before improvement, the improved method of checking fiducial marks and piercing holes involved only 18 motions whereas there were 25 motions for the current inspection method. Besides that, current method took $211.50 \mathrm{sec}$ for checking piercing holes and fiducial marks for 12 panels. Improved inspection method took only $166.05 \mathrm{sec}$ to complete the process. It saved $45.45 \mathrm{sec}$ for every 12 panels which was equivalent to an improvement of $21.5 \%$. 


\subsubsection{Analysis of checking stiffeners (improved)}

In this process, it was suggested that, two panels were checked at the same time in order to eliminate the reaction time of taking and putting down the marker pen as well as time taken to open and close the marker pen cap. Even though the time saved was not much, however, this value would become significant as the size of the lot is large. Besides that, this improvement intended to ease the process of orient the panels back to original arrangement. The performance was measured and was presented in Table 9.

Table 9: Flow process chart of checking stiffener (improved).

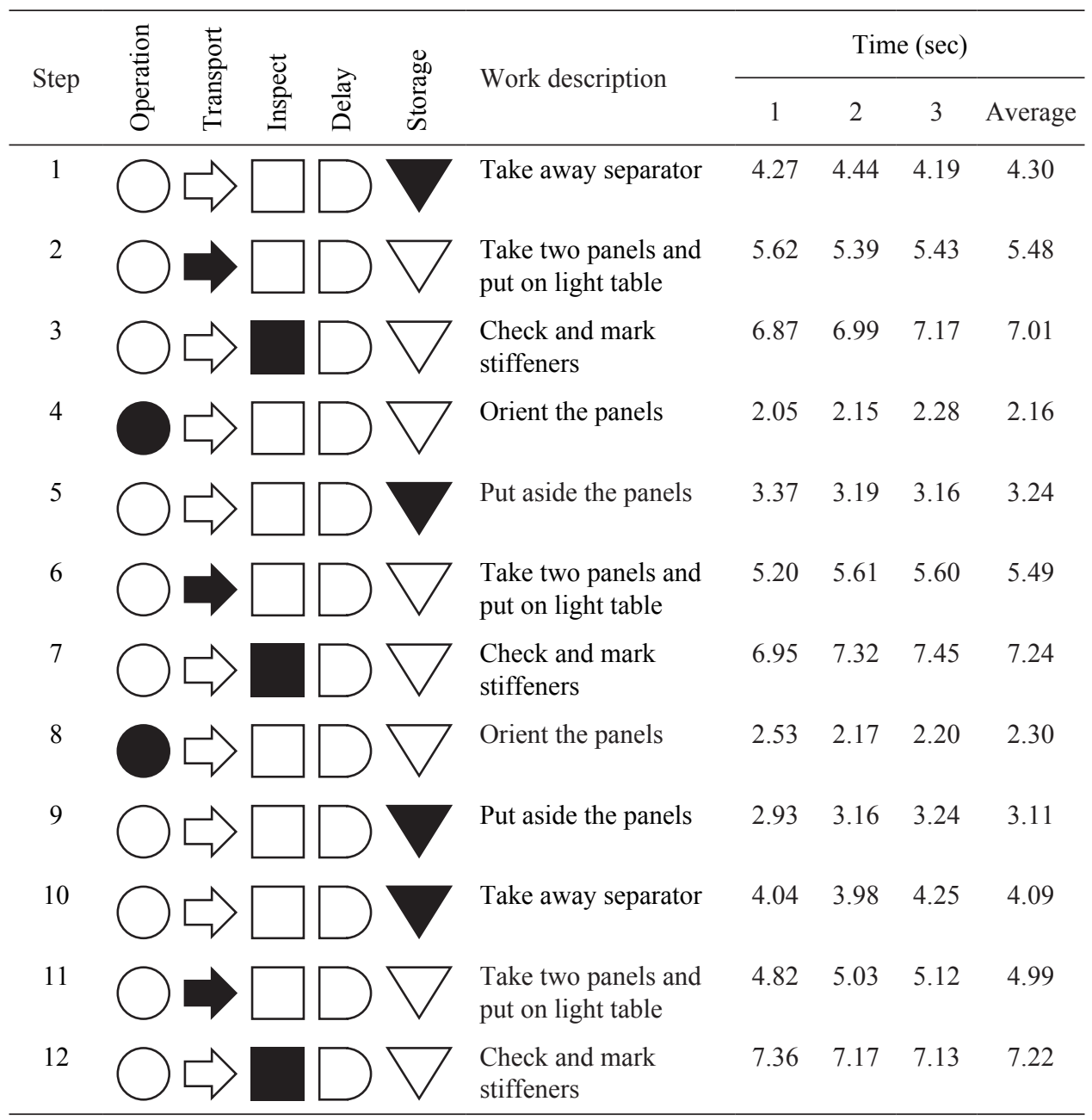


Table 9 (Continued)

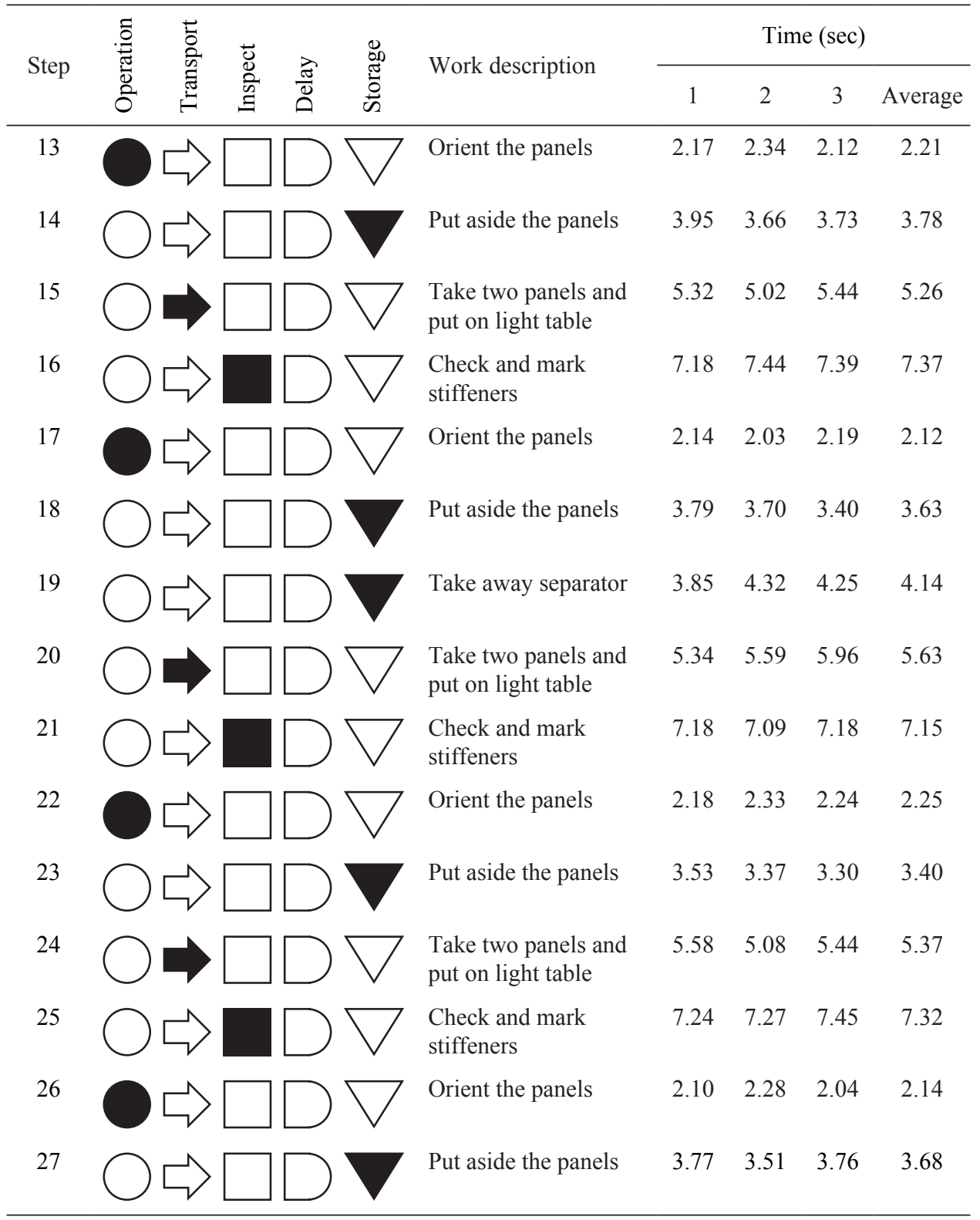

In this improved method, marker pen was taken and put down, opened and closed pen cap for six times only as compared to 12 times before improvement. The time used in this improved method was $146.02 \mathrm{sec}$ as compared to before improvement was $185.63 \mathrm{sec}$. It saved $39.61 \mathrm{sec}$ for every 12 panels which was 
equal to $21.3 \%$. The inspection method for Product 12951 was successfully improved where $45.45 \mathrm{sec}$ was saved for the fiducial marks and piercing holes checking process for every 12 panels. For the process of stiffeners inspection, $39.61 \mathrm{sec}$ was saved for every 12 panels. The result was presented graphically in Figure 9.

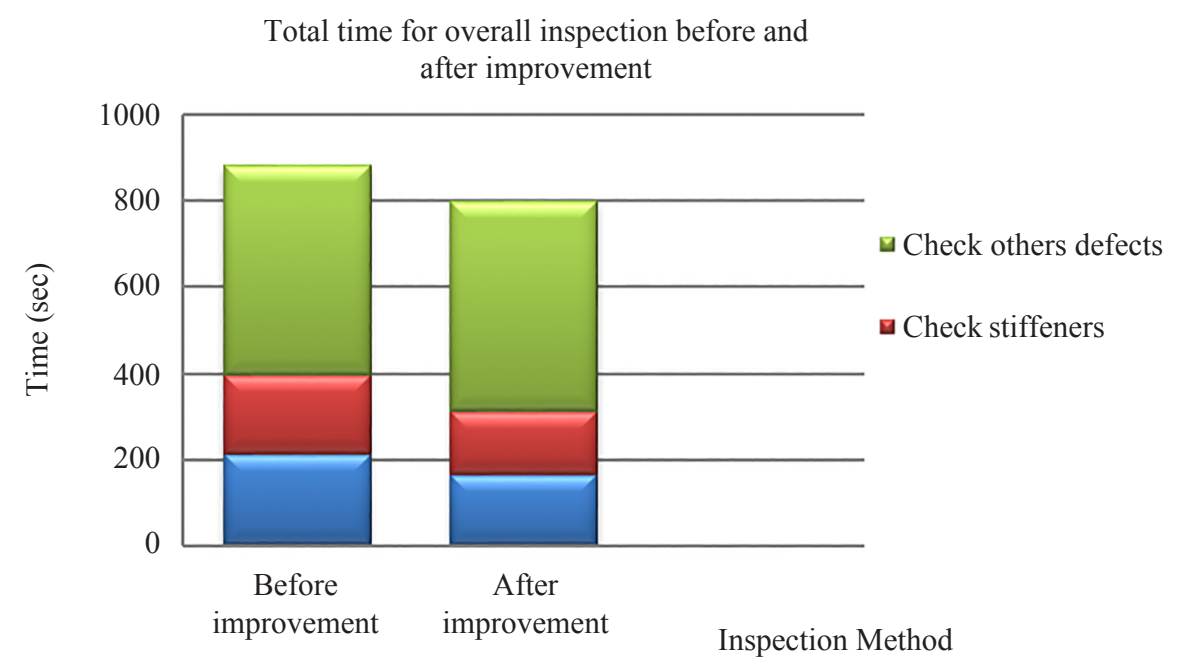

Figure 9: Graph of total inspection time before and after improvement.

As can be seen from Figure 9, total time before improvement was $884.52 \mathrm{sec}$. However, the improved method took only $799.46 \mathrm{sec}$ only. Hence, total of $85.06 \mathrm{sec}$ was saved for every inspection of 12 panels. The time saved would be more significant as the number of panels in one lot increased. Besides improvement in terms of quantitative, it may also improvement in terms of qualitatively which may reduce the number of escapees.

\section{CONCLUSION}

This study was carried at a flexible printed circuit board manufacturer which has a lot of WIP. Hence a methodology was developed to improve the current inspection method of the products which was able to reduce the total inspection time of selected product. A product was selected as the focus to be studied. The product selected was PMC part of number 12951. This PMC part was used for automotive purpose. PMC parts were usually in long rectangular shape. Therefore, the improved method developed for the selected product was actually applicable to other PMC parts. In this study, graphical analysis tool was used to analyse the performance of current. After recognising the performance of current inspection 
method, improvement was made in order to reduce the inspection time. This was done by eliminating unnecessary motions, combining motions to reduce stops and starts of the process. Some of the process sequences were changed to make the sequence more orderly which eventually reduce the inspection time of the product. By using these methods, the current inspection method was modified and rearranged. The total inspection time was successfully reduced by total of $85.06 \mathrm{sec}$ for every 12 panels. This value will become more significant if the lot size increases. Besides reducing the inspection time, this developed improvement method was also able to reduce the number of escapees. However, this performance could not be measured because there was not much production for Product 12951 when this project was carried. But it was believed that it can reduce the probability of defected products being sent to customers. As a conclusion, the inspection time of products decreases, the productivity will increase and hence reduce the amount of WIP in the department.

\section{REFERENCES}

1. Drury, C. G. \& Sinclair, M. A. (1983). Human and machine performance in an inspection task. Hum. Factors, 25(4), 391-399, https://doi.org/ 10.1177/001872088302500404.

2. Khasawneh, M. T., Kaewkuekool, S., Bowling, S. R., Desai, R., Jiang, X., Duchowski, A. T. \& Gramopadhye, A. K. (2003). The effects of eye movements on visual inspection performance. In IIE annual conference proceedings. Norcross, GA: Institute of Industrial and Systems Engineers (IISE).

3. Drury, C. G. (1978). Integrating human factors in statistical process control. Hum. Factors, 20(5), 561-570, https://doi.org/10.1177/ 001872087802000506.

4. Drury, C. G. (1992). Inspection performance. In Engineering. New York: John Wiley and Sons, 2282-2314.

5. Megaw, E. D. (1979). Factors affecting visual inspection accuracy. Appl. Ergon., 10(1), 27-32, https://doi.org/10.1016/0003-6870(79)90006-1.

6. Gramopadhy, A. K. \& Wilson, K. (1997). Noise, feedback training and visual inspection performance. Int. J. Ind. Ergon., 20(3), 223-230, https://doi.org/10.1016/S0169-8141(96)00051-0.

7. Hata, S. (2006). Human factors of visual inspection systems in production. In IEEE industrial electronics, IECON 2006 - 32nd annual conference. Paris: Institute of Electrical Electronics Engineers (IEEE), 5454-5457. 
8. Lee, F. C. H. \& Chan, A. H. S. (2009). Effects of magnification methods and magnifier shapes on visual inspection. Appl. Ergon., 40(3), 410-418, https://doi.org/10.1016/j.apergo.2008.11.005.

9. Garrett, S. K., Melloy, B. J. \& Gramopadhye, A. K. (2001). The effects of per-lot and per-item pacing on inspection performance. Int. J. Ind. Ergon., 27(5), 291-302, https://doi.org/10.1016/S0169-8141(00)00057-3.

10. Tetteh, E., Jiang, X., Mountjoy, D., Seong, Y. \& McBride, M. (2008). Evaluation of job aiding tools in visual system. Hum. Factors Ergon. Manuf., 18(1), 30-48, https://doi.org/10.1002/hfm.20094.

11. Tetteh, E. G. \& Jiang, S. (2006). The effects of search strategy, task complexity and pacing on visual inspection performance. In The proceedings of the 9th annual applied ergonomics conference, Orlando, Florida. Norcross, GA: IISE.

12. Jiang, X., Gramopadhye, A. K., Melloy, B. J. \& Grimes, L. W. (2003). Evaluation of best system performance: Human, automated and hybrid inspection systems. Human Factors and Ergonomics in Manufacturing and Service Industries, 13(2), 137-152, https://doi.org/10.1002/hfm .10031 .

13. Chiang, H. -Q. \& Hwang, S. -L. (1988). Human performance in visual inspection and defect diagnosis tasks: A case study. Int. J. Ind. Ergon., 2(3), 235-241, https://doi.org/10.1016/0169-8141(88)90024-8.

14. Yeow, P. H. P \& Sen, R. N. (2004). Ergonomics improvements of the visual inspection process in a printed circuit assembly factory. Int. J. Occup. Saf. Ergon., 10(4), 369-385, https://doi.org/10.1080/10803548 .2004.11076622.

15. Townsend, J. W., Prien, E. P. \& Johnson Jr, J. T. (1974). The use of the position analysis questionnaire in selecting correlates of job performance among mentally retarded workers. J. Vocat. Behav., 4(2), 181-192, https://doi.org/10.1016/0001-8791(74)90103-1.

16. Aft, L. S. (1983). Productivity measurement and improvement. Marietta, Georgia: Reston Publishing Company.

17. Hockey, G. R. J., Gaillard, A. W. K. \& Burov, O. (1999). Operator functional state. NATO Science Series, vol. 355. Amsterdam: IOS Press and Kluwer Academic Publisher. 